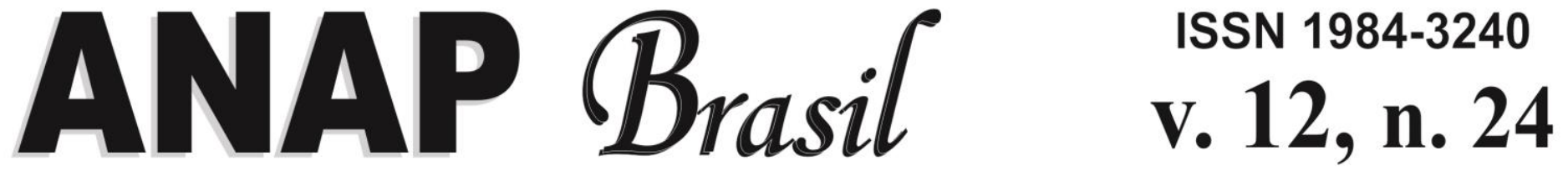

\title{
Comparação do solo-cimento auto adensável convencional e com adição de sílica ativa
}

Comparison of soil-cement self-compacting and with addition of active silica

Comparación del suelo-cemento auto adensado convencional y con adición de sílice activa

Caroline Graminha Gilio

Mestranda, UNESP, Brasil carolinegraminhagilio@gmail.com

Camila Akemi Sakamoto

Graduada, UNESP, Brasil. sakamotocamila@hotmail.com

Vitória Alves Figueiredo

Graduanda, UNESP, Brasil. vitoria.figueiredo97@gmail.com

Marco Antônio de Morais Alcântara Professor Doutor Eng. Civil, UNESP, Brasil. alcantar@dec.feis.unesp.br 


\section{RESUMO}

O trabalho tem como tema, o estudo do solo-cimento com adição do fíler sílica ativa em sua composição. Assim, utilizando uma metodologia experimental, se analisou as características adquiridas pelo solo-cimento auto adensável com a adição da sílica ativa, comparando com as características do solo-cimento convencional, tanto no estado fresco quanto no estado endurecido. A partir de uma análise da composição dos materiais, que auxiliaram o entendimento da produção, pode-se aplicar no campo experimental, a produção de corpos de prova cilíndricos de dois tipos, um tido como referencial, sem fíler e outro, com a adição da sílica ativa. A pesquisa contribuiu na compreensão dos ganhos e das perdas para o material solo-cimento com o acréscimo desse fino, pelos ensaios reológicos, e também ensaios de compressão, mostrando que pode ser considerado uma adição significativa para melhorar o desempenho do material.

The work has as its theme, the study of the soil-cement with addition of the active silica filler in its composition. Thus, using an experimental methodology, the characteristics acquired by the self-compacting soil-cement with the addition of active silica were analyzed, comparing with the characteristics of the conventional soil-cement, both in the fresh state and in the hardened state. From the analysis of the composition of the materials, which helped to understand the production, one can apply in the experimental field, the production of cylindrical specimens of two types, one considered as referential, without filer and another, with the addition of silica. The research contributed to the understanding of the gains and losses for the cement soil material with the addition of these fine by the rheological tests, as well as compression tests, showing that it can be considered a significant addition to improve the performance of the material.

El trabajo tiene como tema, el estudio del suelo-cemento con adición del fíler sílice activa en su composición. Así, utilizando una metodología experimental, se analizó las características adquiridas por el suelo-cemento autoadhesivo con la adición de la sílice activa, comparando con las características del suelo-cemento convencional, tanto en el estado fresco y en el estado endurecido. A partir de un análisis de la composición de los materiales, que auxiliaron el entendimiento de la producción, se puede aplicar en el campo experimental, la producción de cuerpos de prueba cilíndricos de dos tipos, uno tenido como referencial, sin fíler y otro, con la adición de la misma, sílice activa. La investigación contribuyó en la comprensión de las ganancias y de las pérdidas para el material suelo cemento con el aumento de ese fino, por los ensayos reológicos, y también ensayos de compresión, mostrando que puede ser considerado una adición significativa para mejorar el desempeño del material.

PALAVRAS-CHAVE: solo-cimento; auto adensável; sílica ativa. 


\section{INTRODUÇÃO}

Atualmente a busca de novas soluções construtivas é o fator que justifica os estudos voltados ao solo-cimento, pela preocupação cada vez maior em cima da reciclagem de resíduos, bem como o emprego viável de novas ferramentas. Além disso, busca-se diminuir os desperdícios nos canteiros de obras, contribuindo cada vez mais para o bem-estar do meio ambiente. Assim, pela abundância de solo, além do baixo custo e facilidade de manuseio, e por ser o solocimento um material apropriado para diversas aplicações em construções, justifica-se seu estudo e pesquisas de aprimoramento, visando apresentar novas alternativas de material, apontando talvez, novas tendências de construções cada vez mais sustentáveis (GRANDE, 2003).

A partir da NBR 1253 (2012), o solo-cimento pode ser definido como um produto endurecido resultante da cura de uma mistura íntima compactada de solo, cimento e água, em proporções estabelecidas através de dosagem. Desta forma, uma determinada quantidade de cimento Portland adicionada, se torna capaz de estabilizar solos e a água capaz de hidratar o cimento.

As misturas de solo-cimento, hoje em dia, estão ligadas às bases para pavimentação e infraestrutura de transportes, podendo também serem aplicadas em fundações de edificações, vedações em edificações, entre outros (LLAJARUNA, 2016).

Existem 3 tipos de produção do solo-cimento: o compactado, o vibrado e o auto adensável. 0 primeiro diz respeito ao mais convencional, que para atingir as características desejadas, necessita compactação para estabilizar. O segundo, também chamado de solo-cimento plástico, seu adensamento ocorre pela vibração. E o terceiro, auto adensável, é o que requer menos energia, uma vez que seu adensamento ocorre por conta de seu peso próprio (SEGANTINI; ALCÂNTARA, 2010).

O solo-cimento que se tratará neste presente artigo será o solo-cimento auto adensável (SCAA), que é produzido com os mesmos materiais adotados para os dos demais tipos, mas com maior teor de cimento na mistura e com adições de aditivos superplastificantes que servem para as condições requeridas de trabalhabilidade e podem atuar no sentido de promover a desfloculação ou dispersão das partículas. Além disso, podem ser adicionados "finos", para que melhore suas características, conferido maior coesão interna e homogeneidade, evitando segregação (LLAJARUNA, 2016).

O fino escolhido para ser utilizado nesse artigo foi a Sílica ativa (SA). Ela é um subproduto da indústria siderúrgica de produção de ligas de silício e é composto de partículas de sílica amorfa esféricas e finas, divididas com diâmetro de 0,1 $\mu \mathrm{m}$. Esse produto apresenta grande reatividade com os produtos de hidratação do cimento Portland, além de proporcionar melhor o empacotamento das partículas de cimento, devido à extrema finura e a forma esférica das partículas, é responsável pela exsudação interna porque bloqueia os canis de fluxo de água, além de proporcionar vários pontos de nucleação, evitando a formação de cristais de hidróxido de cálcio $(\mathrm{CH})$. Isso porque, o SA por ter uma atividade pozolânica, reage com $\mathrm{CH}$ que foi liberado pela reação do cimento com a água, e forma o silicato de cálcio hidratado (C-S-H) com baixa relação $\mathrm{Ca} / \mathrm{Si}$, fazendo com que o C-S-H seja capaz de se fixar com íons como álcalis e o 


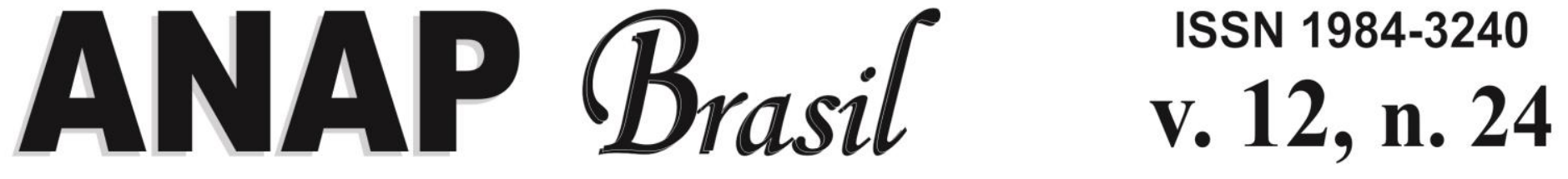

alumínio, a assim, aumentando a resistência do material a ambientes agressivos, por isso hoje altamente empregada para a obtenção de concretos de alto desempenho (BARATA, 1998).

Assim, se tratando de concretos e argamassas, a adição de sílica ativa pode trazer consequências benéficas como: aumento da resistência mecânica à compressão e tração, redução da fluência, melhoria da resistência ao ataque por sulfatos e cloretos. A pesquisa busca saber se essas melhorias existirão não só com o cimento, mas também com o solo (GRANDE, 2003).

\section{OBJETIVOS}

Pelo exposto, o trabalho tem como objetivo, analisar quais as perdas e os ganhos para o material solo-cimento auto adensável, com o acréscimo da sílica ativa, mostrando quais características o novo elemento acrescenta à mistura, tanto no estado fresco, quanto no endurecido.

\section{METODOLOGIA}

Foram realizados ensaios no Laboratório de Materiais e Solos do Departamento de Engenharia Civil da UNESP - Campus de Ilha Solteira - SP.

\subsection{MATERIAIS UTILIZADOS}

\subsubsection{Cimento}

O cimento utilizado para confecção do SCAA foi o Cimento Portland CP 2-Z. Este cimento apresenta uma rápida velocidade de hidratação nos primeiros dias de cura, proporcionando à mistura, uma alta resistência inicial nas primeiras idades.

\subsubsection{Solo}

O solo utilizado nos experimentos tem origem da jazida pertencente ao município de llha Solteira - SP e é classificado como um Argissolo. Para a caraterização do material realizou-se o ensaio de massa específica e granulometria, conforme a NBR 6457 (ABNT, 1986) e NBR 7181 (ABNT, 2016), respectivamente. $O$ valor da massa específica aparente encontrada foi de 1,2 $\left(\mathrm{g} / \mathrm{cm}^{3}\right)$. A Figura 1 mostra a curva granulométrica do solo e areia utilizados na pesquisa. 


\section{ANAP Brasil $^{\prime}$

Figura 1. Curva Granulométrica do Argissolo e da Areia Média Natural.

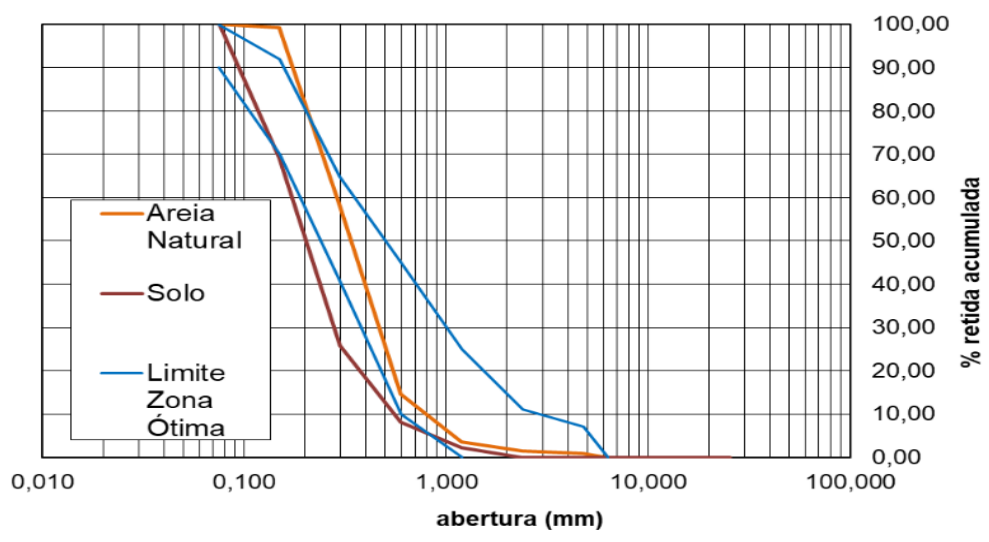

Fonte: Elaborado pelos autores, 2018.

\subsubsection{Areia}

A Areia Média Natural utilizada como agregado na presente pesquisa, foi extraída do Porto Nossa Senhora Aparecida e Pedreira Três Irmãos, de Andradina - SP. A sua curva granulométrica está representada na Figura 1.

\subsubsection{Aditivo}

$\mathrm{O}$ aditivo utilizado foi o Sika ViscoCrete $20 \mathrm{HE}$, um aditivo superplastificante que permite a redução de água na mistura, a dispersão das partículas e garante melhor coesão interna no traço, foi adotado dentro de um teor com relação ao cimento que impede que a mistura apresente segregação ou exsudação. Além disso, atende os requisitos da norma NBR 11768 (ABNT, 2011).

\subsection{5 Água}

A água utilizada na pesquisa foi a disponível no laboratório que é proveniente do abastecimento público de Ilha Solteira - SP.

\subsubsection{Fíler}

Com base nos ensaios de caracterização física e química da Sílica Ativa (tipo de Fíler utilizado no trabalho) apresentados por Mendes (2002) a massa específica e umidade da Sílica Ativa são de $2,2\left(\mathrm{~g} / \mathrm{cm}^{3}\right)$ e $1,2(\%)$, respectivamente, a composição química pode ser verificada na Tabela 1. 

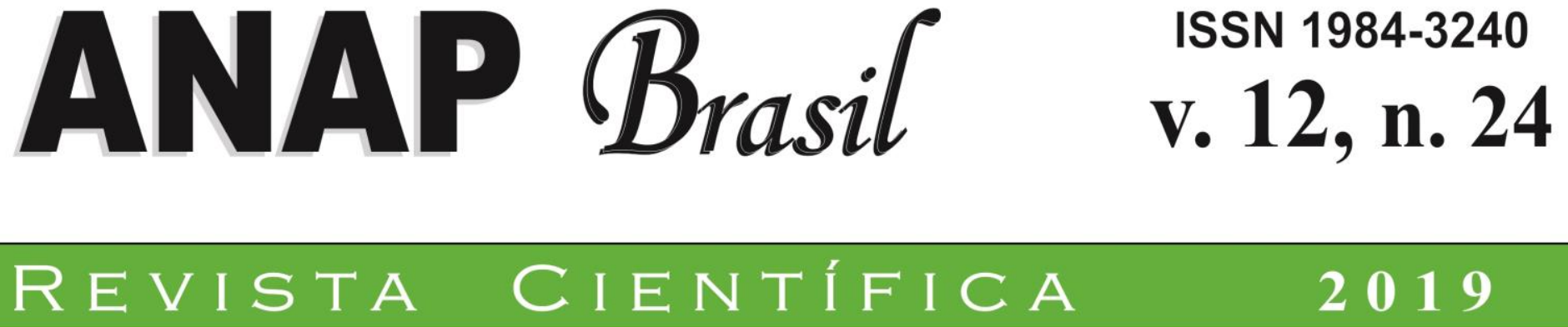

CI E N TÍFI C A

2019

\begin{tabular}{cc} 
Tabela 1. Caracterização Química da Sílica Ativa. \\
\hline Ensaios Químicos & Teores (\%) \\
\hline Perda ao Fogo & 2,64 \\
Óxidos de Sílica $\left(\mathrm{SiO}_{2}\right)$ & 96,09 \\
Óxidos de Sódio $\left(\mathrm{Na}_{2} \mathrm{O}\right)$ & 0,51 \\
Óxidos de Potássio $\left(\mathrm{K}_{2} \mathrm{O}\right)$ & 0,86 \\
Equivalente Alcalino em $\mathbf{N a}_{2} \mathbf{O}$ & 1,10 \\
\hline
\end{tabular}

Fonte: Mendes, 2002.

\subsection{PROCEDIMENTO EXPERIMENTAL}

\subsubsection{Definição dos traços}

Foram confeccionados dois traços de solo-cimento auto adensável (SCAA), o primeiro traço foi produzido sem adição de fíler e nomeado como traço de referência, enquanto que o segundo traço (T-1) foi confeccionado com adição de 5,67\% de fíler em relação a quantidade de cimento.

O traço referência foi confeccionado com relação água/cimento de 2,33 e adição de $3 \%$ (em relação ao peso do cimento) de aditivo superplastificante.

O traço com adição de fíler foi confeccionado com os mesmos materiais e quantidades do traço referência, apenas foi acrescentado 5,67\% de fíler (em relação ao peso de cimento).

A Tabela 2 apresenta a composição dos traços referência e T-1.

Tabela 2. Quantidade dos materiais utilizados nos traços em Kg.

\begin{tabular}{ccccccc}
\hline Traço & Solo & Cimento & Fíler & Areia & Água & Aditivo \\
\hline Referência & 7,50 & 1,50 & 0 & 1,46 & 3,50 & 0,045 \\
T-1 & 7,50 & 1,50 & 0,085 & 1,46 & 3,50 & 0,045 \\
\hline
\end{tabular}

Fonte: Elaborado pelos autores, 2018.

\subsubsection{Confecção das Misturas}

Para confecção das misturas, primeiro foram misturados os materiais secos por aproximadamente 1 minuto, logo após, adicionou-se 2/3 da água misturando por um minuto, posteriormente, adicionou-se o restante da água e o aditivo, realizando a homogeneização por mais um minuto. A Figura 2 representa a homogeneização da mistura na betoneira. 


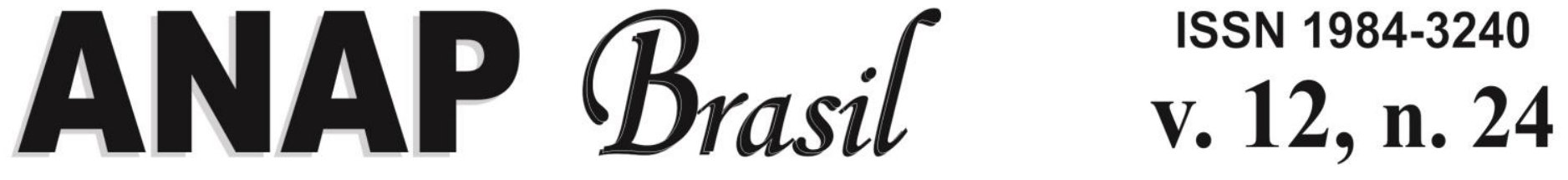

REVISTA CIENTÍFICA 2019

Figura 2. Homogeneização do solo-cimento na betoneira.

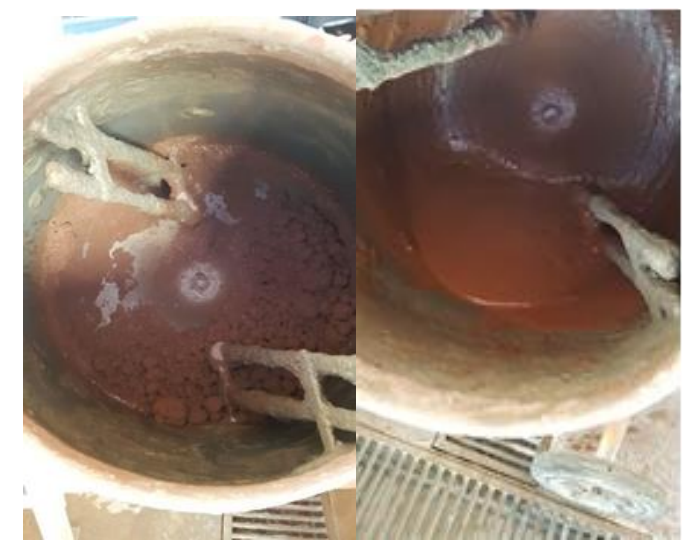

Fonte: Elaboradas pelos autores, 2018.

\subsubsection{Ensaios no Estado Fresco}

\subsubsection{Ensaio de Espalhamento "Slump Flow"}

O Ensaio de Espalhamento tem por finalidade verificar a viscosidade, consistência e coesão interna das misturas. Este ensaio foi realizado com base na NBR 15823 - 2 (ABNT,2010) e consiste em preencher um tronco de cone metálico, apoiado em uma mesa, com o SCAA que está sendo estudado. Após o preenchimento regularizou-se a superfície e retirou-se o tronco de cone no sentido ascendente. Ao retirar o tronco de cone a mistura apresentou um espalhamento livre sobre a mesa. O diâmetro do espalhamento foi determinado considerando-se locais com homogeneidade e maior concentração de material, não sendo levado em conta as partes com exsudação no perímetro do círculo de espalhamento (Figura 3).

Figura 3. Espalhamento da composição de referência e a da composição T-1, respectivamente.

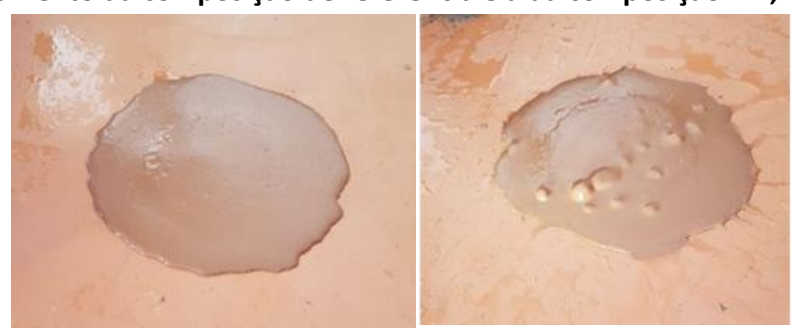

Fonte: Elaboradas pelos autores, 2018.

\subsubsection{Ensaio do Funil}

O ensaio do funil tem como objetivo estudar a fluidez, viscosidade e atrito interno da mistura. O funil utilizado no procedimento foi confeccionado a partir de garrafa Pet. O ensaio consistiu em colocar a mistura no funil, o qual foi mantido com a parte inferior lacrada. Após o 


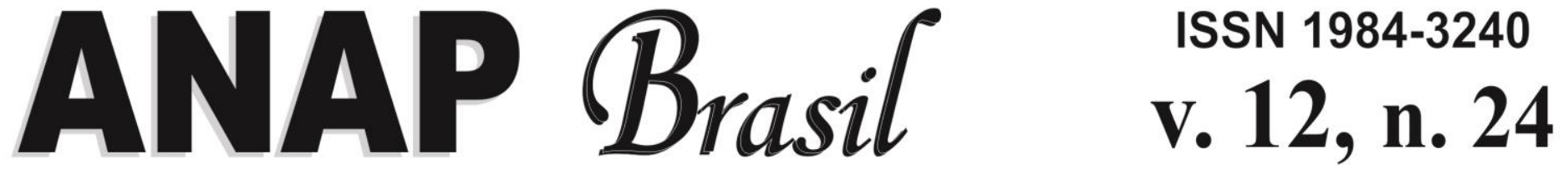

preenchimento do funil realizou-se a abertura do funil (Figura 4) e o acionamento do cronômetro, simultaneamente, com a finalidade de determinar o tempo de escoamento da massa colocada no funil até que o mesmo parasse de escoar, sendo por todo material ter passado, ou por alguma obstrução na passagem. O próximo passo foi então, pesar a massa passante no funil para determinar o fluxo de massa no funil. $O$ resultado é expresso em gramas por segundos. Este ensaio não é normalizado para solo-cimento auto adensável, mas se assemelha ao Ensaio de Determinação de Fluidez das pastas de cimentos prescritos pela NBR 7681-2(ABNT, 2013) o qual foi utilizado como base para este ensaio.

Figura 4. Representação do ensaio do funil.

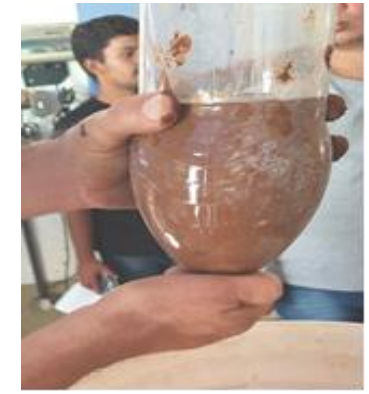

Fonte: Elaborada pelos autores, 2018.

\subsubsection{Ensaio de Segregação (Peneiramento)}

O ensaio de peneiramento tem por objetivo determinar a floculação, segregação e avaliar a estabilidade das misturas, com base no valor da porcentagem passante no SCAA. Este ensaio não é normalizado, mas consiste em uma variação do ensaio de segregação por peneiramento para concretos, prescrito pela Association Française de Génie Civil A.F.G.C (2000). Para iniciar este ensaio foi realizada a pesagem da peneira de abertura de $4,80 \mathrm{~mm}$ e seu fundo, posteriormente, despejou-se $2 \mathrm{~kg}$ no conjunto (peneira + fundo), e após o peneiramento, retirou-se a peneira e verificou-se a massa passante pela peneira. Com isso, o que se obteve foi a porcentagem de SCAA que passou pela peneira em relação ao que foi despejado nesta. A Figura 5 ilustra o aparato experimental. 


\section{ANAP Brasil $^{\prime}$

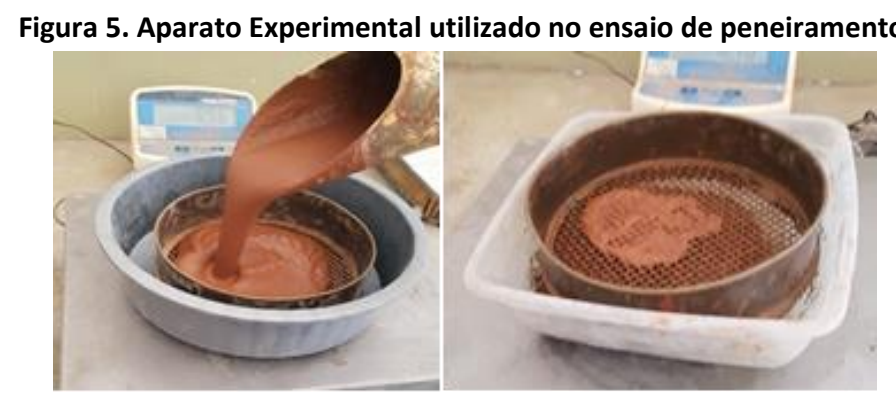

Fonte: Elaboradas pelos autores, 2018.

\subsubsection{Ensaios no Estado Endurecido}

No estado endurecido foram realizados ensaios de resistência à compressão axial, diametral, e absorção de água de acordo com as NBR 12025 (ABNT, 2012B), NBR 7222 (ABNT, 2011) e NBR 13555 (ABNT 2012C), respectivamente. Conforme orientado pelas normas, confeccionou-se para a idades de ruptura de 7 e 28 dias, 3 corpos de prova cilíndricos de $5 \times 10 \mathrm{~cm}$ para cada traço e para cada ensaio. Na ruptura dos corpos de prova no ensaio de compressão axial e diametral foi utilizada a prensa universal de ensaios.

\section{RESULTADOS}

\subsection{RESULTADOS DOS ENSAIOS NO ESTADO FRESCO}

\subsubsection{Resultados do Ensaio de Espalhamento "Slump Flow"}

A Tabela 3 apresenta os diâmetros médios de espalhamento obtidos no ensaio Slump Flow para o traço de referência e para o traço T-1 com adição de 5,67\% de fíler.

Tabela 3. Diâmetros de espalhamento obtidos para o traço referência e traço T-1.

\begin{tabular}{ccc}
\hline Traço & Adição de Fíler (\%) & Diâmetro de espalhamento (cm) \\
\hline Referência & 0 & 31,0 \\
T-1 & 5,67 & 29,5 \\
\hline
\end{tabular}

Fonte: Elaborado pelos autores, 2018.

Como pode ser observado na Tabela 3 o espalhamento do traço T-1 diminuiu em relação ao traço referência. Essa diminuição do "Slump flow" pode ser explicada pela adição do fíler que provocou um aumento da viscosidade e coesão interna diminuindo, portanto, o diâmetro de espalhamento da ordem de 1,5 centímetros. Contudo não comprometeu as condições de mobilidade no escoamento livre. 


\section{ANAP Brasil $^{\prime}$

\subsubsection{Resultados do Ensaio do Funil}

Os resultados obtidos no ensaio do funil, o tempo de queda das misturas, o peso da massa passante pelo funil e a consequente vazão mássica, encontram-se especificados na Tabela 4.

Tabela 4. Resultados obtidos no Ensaio do Funil para o traço referência e traço T-1.

\begin{tabular}{ccccc}
\hline Traço & Adição de Fíler (\%) & Tempo (s) & Massa (g) & Vazão Mássica (g/s) \\
\hline Referência & 0 & 3,41 & 1390 & 407,62 \\
T-1 & 5,67 & 7,25 & 1490 & 205,52 \\
\hline
\end{tabular}

Fonte: Elaborado pelos autores, 2018.

Os Resultados do Ensaio do Funil mostram que a vazão mássica diminui da ordem de $202,1 \mathrm{~g} / \mathrm{s}$ com a adição de Fíler, esta diminuição da vazão mássica é proveniente da diminuição da fluidez, aumento da viscosidade e do atrito interno da mistura com a adição de Fíler. Contudo não comprometeu as condições de viabilidade do escoamento confinado.

\subsubsection{Resultados do Ensaio de Segregação (Peneiramento)}

Para o traço referência e o traço T-1 foi determinado a quantidade de massa passante e a porcentagem da massa que passou pela peneira em relação aos $2 \mathrm{Kg}$ colocados. Estes resultados estão apresentados na Tabela 5.

Tabela 5. Quantidade de massa que passa pela peneira e a porcentagem que passante para o traço referência e traço T-1.

\begin{tabular}{cccc}
\hline Traço & Adição de Fíler (\%) & Massa Passante (kg) & Porcentagem Passante (\%) \\
\hline Referência & 0 & 1,88 & 94 \\
T-1 & 5,67 & 0,36 & 18 \\
\hline
\end{tabular}

Fonte: Elaborado pelos autores, 2018.

Comparando-se a porcentagem passante de massa pela peneira para o traço referência e o traço T-1, observou-se que a porcentagem passante de massa no traço T-1 é aproximadamente 5 vezes menor que no traço referência, essa diminuição foi ocasionada pela maior interatividade físico-química da mistura e consequente floculação com a adição do Fíler. 


\section{ANAP Brasil $^{\prime}$

$\mathrm{Na}$ análise da razão entre a resistência à Compressão Diametral e Axial para os dois traços estudados obteve-se, como resultado, uma razão de 0,18 para o traço referência e 0,11 para o traço T-1, da mesma forma que para a idade de ruptura de 7 dias, os corpos de prova com o traço T-1 são menos dúcteis quando comparados com o traço referência.

Não obstante o aumento da fragilidade, ao comparar as resistências das duas idades de ruptura, verificou-se a ocorrência de um ganho de resistência tanto Axial e diametral para os dois traços aos 28 dias.

\subsubsection{Resultados do Ensaio de Absorção}

No que se refere ao ensaio de absorção temos que a massa seca dos corpos de prova foi obtida após o armazenamento por 24h na estufa, já a massa úmida refere-se ao peso após a imersão por $24 \mathrm{~h}$ do corpo de prova. Os resultados para cada composição nos ensaios de 7 e 28 dias estão apresentados na Tabela 8 e Tabela 9, respectivamente.

Tabela 8. Resultados do ensaio de absorção 7 dias.

\begin{tabular}{ccccccc}
\hline & \multicolumn{2}{c}{ Massa seca (g) } & \multicolumn{2}{c}{ Massa úmida (g) } & \multicolumn{2}{c}{ Umidade (\%) } \\
\hline & Referência & T-1 & Referência & T-1 & Referência & T-1 \\
\hline $\begin{array}{l}\text { Média } \\
\text { Desvio } \\
\text { Padrão }\end{array}$ & 246,94 & 265,22 & 311,69 & 328,15 & 26,22 & 23,73 \\
Coef. & 6,33 & 2,16 & & & & 0,01 \\
Var. (\%) & 2,56 & 0,81 & 2,07 & & 0,03 & 0,02 \\
\hline
\end{tabular}

Tabela 9. Resultados do ensaio de absorção 28 dias.

\begin{tabular}{|c|c|c|c|c|c|c|}
\hline & \multicolumn{2}{|c|}{ Massa seca (g) } & \multicolumn{2}{|c|}{ Massa úmida (g) } & \multicolumn{2}{|c|}{ Umidade (\%) } \\
\hline & Referência & $\mathrm{T}-1$ & Referência & $\mathrm{T}-1$ & Referência & $T-1$ \\
\hline Média & 251,29 & 253,86 & 316,02 & 315,13 & 25,74 & 24,13 \\
\hline \multicolumn{7}{|l|}{ Desvio } \\
\hline Padrão & 7,76 & 8,66 & 12,47 & 10,59 & 1,62 & 0,13 \\
\hline \multicolumn{7}{|l|}{ Coef. } \\
\hline Var. (\%) & 3,09 & 3,41 & 3,95 & 3,36 & 6,28 & 0,53 \\
\hline
\end{tabular}

Comparando-se a as umidades médias entre as idades verifica-se que não tem uma variação expressiva, ou seja, que a idade de cura não tem grande interferência na absorção dos corpos 


\section{ANAP

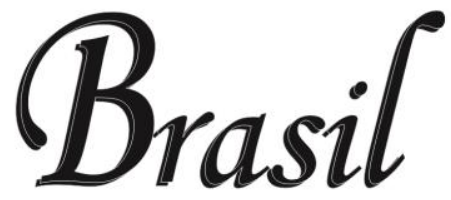 \\ ISSN 1984-3240 V. 12, n. 24}

de prova. A única conclusão que pode ser observada comparando as idades é o caráter higroscópico do fíler.

Quando se compara os corpos de prova referência e com adição de fíler, observa uma variação significante no quesito absorção, observando-se que o fíler garante ao corpo de prova uma menor absorção causada provavelmente pela maior cimentação devida as partículas mais finas do fíler.

\section{CONCLUSÃO}

A preocupação cada vez maior em cima de novas soluções construtivas que priorizam a sustentabilidade e uso de novos materiais alternativos, para diminuir os excessos provenientes da construção civil e pensando num desenvolvimento sustentável, fez com que se buscasse entender o comportamento do solo-cimento auto adensável com a adição da sílica ativa. Por ela ser um subproduto da indústria siderúrgica, e por ter grande reatividade com o cimento Portland, por sua extrema finura, faz com que se atribua novas características ao solo-cimento, se comparado ao convencional.

O que pode notar é que, no caráter reológico da mistura, comparando a convencional e a com a adição do fino, a mistura com a sílica ativa fez com que houvesse maior floculação da massa, assim como a tornou mais coesa, menos fluida, com maior viscosidade, pois aumentou o atrito interno entre as partículas, uma vez que aumentou a concentração de finos e com isso a diminuição dos vazios. Com relação aos ensaios com o material já endurecido, concluiu-se que o solo-cimento com o fíler perdeu resistência à tração, tornando-o menos dúctil, fato coerente com o aumento expressivo do patamar de resistência; aumentou consideravelmente no ensaio da compressão axial. Além disso, para a absorção, o caráter higroscópico do material, que bloqueia os fluxos de água, fez com que se diminuísse a absorção do conjunto.

Assim, conclui-se que considerando algumas perdas que a adição da sílica ativa possa causar ao solo-cimento, os ganhos são consideravelmente maiores, e ela pode ser sim uma adição de material alternativo positivo para a construção civil.

\section{AGRADECIMENTO}

Os autores agradecem ao Professor Marco Antônio de Morais Alcântara por toda dedicação e aos laboratoristas da UNESP/FEIS (Universidade Estadual Paulista / Faculdade de Engenharia Ilha Solteira), pelo auxilio.

\section{REFERÊNCIAS BIBLIOGRÁFICAS}

ASSOCIAÇÃO BRASILEIRA DE CIMENTO PORTLAND - ABCP. Dosagem das misturas de solocimento - normas de dosagem. São Paulo: ABCP, Estudo Técnico ET-35, 1986. 


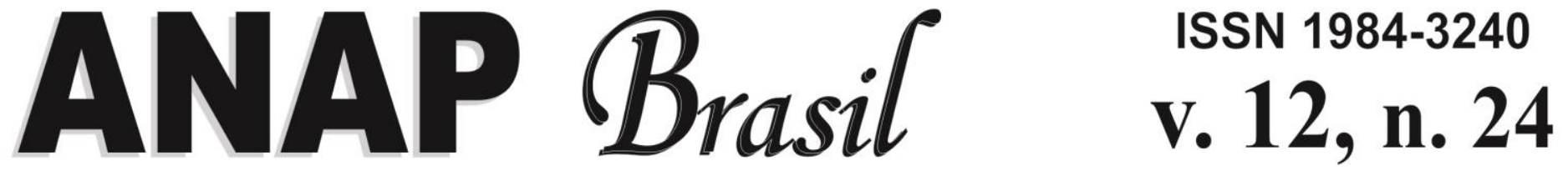

\section{REVISTA CIENTÍFICA 2019}

MENDES, S. E. da S. Estudo experimental de concreto de alto desempenho utilizando agregados graúdos disponíveis na região metropolitana de Curitiba. Dissertação (Mestrado em Construção Civil) - Universidade Federal do Paraná, Curitiba, 2002.

SEGANTINI, A. A. S.; ALCANTARA, M. A. M. Solo-cimento e solo-cal. In: INSTITUTO BRASILEIRO DE CONCRETO - IBRACON (Org.). Materiais de construção civil e princípios básicos de ciência e engenharia de materiais. 2. ed. São Paulo: IBRACON, 2010. v. 2, p. 863-891. 